Rev Biomed 2006; 17:1-2.

\title{
Retos de la producción científica en la biomedicina mexicana.
}

Renán A. Góngora-Biachi.

Editor, Revista Biomédica, Centro de Investigaciones Regionales "Dr. Hideyo Noguchi", Universidad Autónoma de Yucatán, Mérida, Yucatán México.

Al considerar que la publicación en revistas científicas ha sido en sí misma revolucionaria, ya que comunica unidades discretas de conocimiento en mucho menor tiempo que el que se requeriría hacerlo a través de un libro, ha sido en gran parte la razón del número creciente de revistas que se editan en todo el mundo (a principios del siglo XIX existían sólo 100 revistas científicas a nivel mundial y en 1992 más de 100,000 revistas, de las cuales aproximadamente el $25 \%$ eran de tipo biomédico).

La publicación científica mexicana, de 1990 a 2000, estaba representada, considerando todas las disciplinas, por 32,726 publicaciones y de éstas 4,553 (13.9\%) eran de índole médica (cuadro I, figura 1). Esta cifra, considerando el número de las disciplinas, no es despreciable. Quizá el reto no alcanzado es el impacto de lo que publicamos.

Pero, los trabajos publicados en revistas científicas (mexicanas o extranjeras), no refleja realmente el quehacer académico de los profesionales dedicados a la Investigación biomédica. Es decir, se publica menos de lo que se produce. Un ejemplo de esta situación, es el hecho que de aproximadamente 220 trabajos libres presentados en los congresos de la agrupación Mexicana para el Estudio de la Hematología, A.C., en 2003 y 2004, publicados como resúmenes, sólo 24 (10.7\%) fueron publicados en extenso. Sucede los mismo en otras disciplinas biomédicas.
Es frecuente oír experiencias anecdóticas, similares a las publicadas en el extranjero o en nuestro país, pero que lamentablemente no tienen el sustento académico de una publicación, a pesar que tal o cual condición había sido reconocida primeramente por los colegas mexicanos.

Al parecer, la mayoría de los profesionales dedicados a la investigación biomédica no han considerado que es solamente a través de la publicación científica como se puede conocer, debatir y verificar las investigaciones, además de que otorga un registro permanente, registro sin el cual no podría progresar la ciencia. Sencillamente, científicamente hablando, lo que no está publicado no existe.

Además, la pobre publicación en el área de la biomedicina en México ha hecho que no se aproveche a las revistas científicas como un medio eficiente de comunicación entre investigadores y como un foro de discusión. La falta de publicaciones ha ocasionado también la ausencia de identidad a grupos de trabajo y la validación académica externa.

¿Por qué no hay más comunicaciones científicas en el área de la biomedicina? La respuesta, a nuestro juicio, es dependiente de varios factores. Entre ellos:

a) La falta de motivación y "entrenamiento" hacia el método científico que se observa desde los niveles de licenciatura.

b) La poca importancia que otorgaron a las publicaciones las generaciones pasadas. El científico

Solicitud de sobretiros: Revista Biomédica, Centro de Investigaciones Regionales "Dr. Hideyo Noguchi", Universidad Autónoma de Yucatán, Av. Itzáes No. 490 x 59, C.P. 97000, Mérida, Yucatán, México. Correo electrónico: revbiomed@mucuy.uady.mx Este artículo está disponible en http://www.uady.mx/sitios/biomedic/revbiomed/pdf/rb061711.pdf 


\section{RA Góngora-Biachi.}

era él por lo que hacía en su laboratorio o servicio clínico, respaldado por su imagen de maestro y no por sus publicaciones.

c) El hecho de no saber escribir un artículo científico.

d) El falso concepto de que las publicaciones son para los "básicos", pero no para los clínicos. En consecuencia, las evaluaciones al desempeño académico y laboral no contemplaban las publicaciones en investigación clínica.

e) La frustración permanente al ser rechazado un artículo, en la revisión por los pares.

f) La falta de trabajo de grupos cooperativos.

Los retos -transformados en metas- a alcanzar por la biomedicina mexicana, para incrementar su publicación científica, tendrían que concebirse tomando en cuenta las consideraciones anteriores. En especial, debe fomentarse permanentemente la publicación científica entre las nuevas generaciones. Es la única manera de que la biomedicina mexicana tendrá el lugar que le corresponde en la ciencia mundial.

Cuadro I

Artículos publicados por científicos mexicanos por disciplina, 1990-2000.

\begin{tabular}{lllllllllllll}
\hline Disciplina & $\mathbf{1 9 9 0}$ & $\mathbf{1 9 9 1}$ & $\mathbf{1 9 9 2}$ & $\mathbf{1 9 9 3}$ & $\mathbf{1 9 9 4}$ & $\mathbf{1 9 9 5}$ & $\mathbf{1 9 9 6}$ & $\mathbf{1 9 9 7}$ & $\mathbf{1 9 9 8}$ & $\mathbf{1 9 9 9}$ & $\mathbf{2 0 0 0}$ & Total \\
\hline Astrofísica & 51 & 76 & 58 & 71 & 107 & 91 & 111 & 131 & 148 & 220 & 172 & 1,236 \\
Agricultura & 80 & 93 & 106 & 139 & 103 & 146 & 108 & 163 & 141 & 157 & 157 & 1,393 \\
Biología & 109 & 137 & 179 & 173 & 196 & 255 & 213 & 292 & 298 & 347 & 326 & 2,525 \\
Ecología & 55 & 57 & 68 & 111 & 79 & 106 & 114 & 154 & 153 & 160 & 208 & 1,265 \\
Física & 213 & 237 & 395 & 426 & 493 & 556 & 650 & 647 & 801 & 954 & 926 & 6,298 \\
Ingeniería & 60 & 78 & 67 & 88 & 95 & 97 & 132 & 146 & 204 & 235 & 237 & 1,439 \\
Medicina & 308 & 267 & 356 & 276 & 306 & 316 & 490 & 503 & 529 & 572 & 630 & 4,553 \\
Microbiología & 62 & 67 & 72 & 81 & 74 & 115 & 100 & 122 & 133 & 133 & 134 & 1,093 \\
Neurociencias & 79 & 78 & 64 & 98 & 104 & 117 & 104 & 111 & 114 & 134 & 114 & 1,117 \\
Plantas y animales & 170 & 191 & 257 & 251 & 328 & 383 & 383 & 425 & 524 & 525 & 573 & 4,010 \\
Química & 141 & 185 & 194 & 236 & 260 & 365 & 408 & 417 & 474 & 512 & 519 & 3,711 \\
Otras disciplinas & 314 & 345 & 413 & 491 & 599 & 640 & 780 & 812 & 901 & 975 & 1,021 & 7,291 \\
Total* & 1,487 & 1,635 & 2,013 & 2,200 & 2,502 & 2,916 & 3,282 & 3,585 & 4,028 & 4,490 & 4,588 & 32,726 \\
\hline
\end{tabular}

Fuente: Institute for Scientific Informatica, 2001.

* La suma de artículos de todas las disciplinas no coincide con el total debido a que existen artículos clasificados en más de una disciplina.

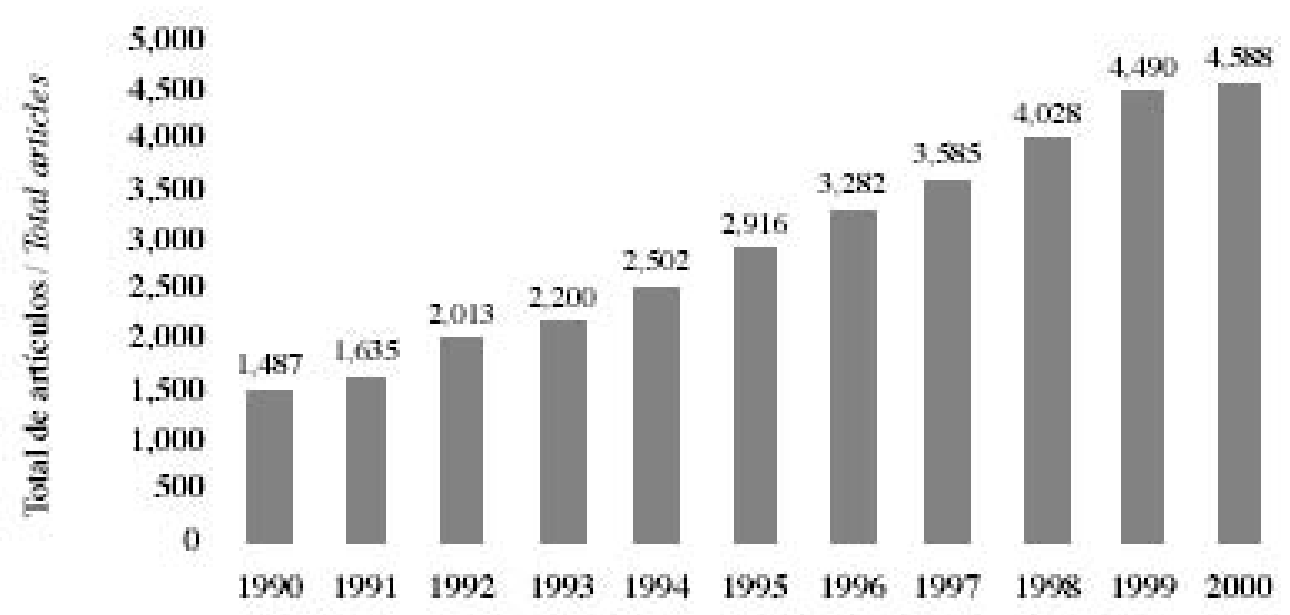

Figura 1.- Total de artículos publicados por científicos mexicanos, 1990-2000. (Fuente JR, Martuscelli J, Alarcón-Segovia D. Resumen de "El futuro de la investigación médica en México", Gaceta Médica Mexicana 2004; 140 (5):519-524. 